\section{Treatment of criminal psychopaths in} Holland

DeAR Sirs

We were fortunate in recently being able to visit the Dutch 'TBR Institutions' for the treatment of psychopathic offenders, which has caused us to reflect upon our approach to these patients in the National Health Service.

Holland has no equivalent of the 1983 Mental Health Act in respect of the disposal of mentally disordered offenders. Offenders who suffer from severe mental illness are liable to be judged as not criminally responsible for their actions, in a manner parallel to the British insanity verdict. Individuals with lesser degrees of mental disturbances, most commonly diagnosed as suffering from personality disorders, may be deemed to be of diminished responsibility for their actions. Serious offenders of this type can be detained indefinitely, at the Governments' pleasure (TBR), subject to judicial review, for the purpose of protecting society against their criminal behaviour. Unlike Britain, where a defence of diminished responsibility is applicable only to those individuals charged with murder, in Holland this concept applies across the spectrum of criminal offences.

Based on these two medico/legal categories of absent or diminished criminal responsibility, Holland has two separate systems for dealing with mentally disordered offenders. Those who suffer from severe mental disorder and are judged not responsible for their actions are committed to psychiatric hospitals, operating within the Health Service. Individuals who are judged to be of diminished responsibility are treated within one of the seven 'TBR Institutions', comprising in total approximately 400 beds, which operate within the orbit of the Ministry of Justice. These institutions offer specialised psychotherapeutic programmes for psychopathic offenders, although the psychotherapeutic school in prominence varies from institution to institution. We could not help but be impressed by the quality of the psychotherapeutic programmes, which appear to have a sophistication and commitment not easily found within British forensic psychiatric services.

The forensic psychiatric services of the National Health Service in England and Wales have to provide treatment for both mentally ill and psychopathic patients. It is our impression that there is considerable uncertainty about the treatment of psychopathic offenders within both our Special Hospitals and Regional Secure Units. We consider that this may, in part, be linked to the inherent difficulties in treating both mentally ill and psychopathic patients within the same setting, as the requirements of these two quite distinct groups vary dramatically; the former requiring medical treatment for their illness and the latter a psychotherapeutic approach to their disorder. We conclude that there may be advantages in the Dutch model in having facilities for the treatment of psychopathic offenders separate from those which offer orthodox treatment for mental illness. It is an area which British forensic psychiatric services might take note of, with advantage.

\section{Norvic Clinic}

C. M. GREEN

\section{St Andrew's Hospital}

Norwich NR7 0SS

Park Lane Hospital

Maghull

Liverpool L31 $1 \mathrm{HW}$

\section{Mental Health Review Tribunals}

\section{DeAR Sirs}

Following Dr Grounds article on Mental Health Review Tribunals (MHRT) (Psychiatric Bulletin, June 1989, 13, 299-300) there have been two interesting comments by Graham Petrie (Psychiatric Bulletin. October 1989, 13, 571) and Herschel Prins (Psychiatric Bulletin, January 1990, 14, 42). The latter is right in pointing out that it is possible to continue to treat a patient on an 'informal basis' after he/she has been discharged by a MHRT. There is no reason why this should not happen in a special hospital. There are two informal patients at Park Lane Special Hospital at present.

It is worth noting that the MHRTs can and do discharge unrestricted patients as well and not uncommonly patients may agree to stay on as informal in-patients until their psychiatric state is further improved and/or adequate aftercare arrangements have been made. Occasionally MHRTs agree to give patients a 'conditional discharge' but defer the date of discharge to give relevant agencies time to fulfil the conditions stipulated. A number of patients apply to the MHRT soon after admission, motivated either by their abnormal mental state or well-meaning legal representatives. When their mental state improves some withdraw their application, and a few others agree to stay in the hospital irrespective of the outcome of the tribunal hearing.

\section{Park Lane Hospital \\ Maghull \\ Liverpool $\mathrm{L} 31 \mathrm{HWW}$}

GIRISH C. SHETTY

\section{Epidemiology of senior psychiatrists}

\section{DEAR SIRS}

Two recent meetings have allowed detailed observations on senior psychiatrists. The first was a meeting of senior organisers for the Part I MRCPsych, 
these being drawn mainly from non-metropolitan, non-teaching areas. The task is fairly hard work, and not highly esteemed. About a quarter of the senior organisers were women, and a similar fraction were non-Caucasian, this being probably not atypical for consultant psychiatrists as a whole.

The second meeting was of the Board of Examiners for Part II of the MRCPsych. This commitment is not terribly hard work, but is highly prestigious. Hardly any of those attending were women, and the overwhelming majority were Caucasian, many of whom had accents strongly suggesting private education, and often holding teaching district appointments.

Is there any explanation for these major differences, or are they an artefact of small samples?

University of Wales College of Medicine

GARETH H. JONES

\section{Whitchurch Hospital}

Cardiff CF4 $7 X B$

\section{DeAR SirS}

Dr Gareth Jones, on the basis of his attendance at two recent meetings, the one of Part I MRCPsych Senior Organisers and the other an Annual Meeting of the Part II Board of Examiners, implies that certain subtle and undesirable factors enter into the selection of Examiners as opposed to Senior Organisers with regard to our College Examinations.

May I hasten to point out that scrupulous care is taken to select Senior Organisers on criteria such as organisational ability, interest in teaching and in the examination process, besides perceived academic ability. There should be no question of the role of Senior Organiser being held in low esteem. All Senior Organisers undertake an induction course similar to that undertaken by Examiners, and part of their role is to examine candidates at their own centres when the need arises. Quite often, as in the case of Dr Jones, one individual may undertake both roles either concurrently, or at different times.

Dr Jones would be welcome to complete the data collection in his epidemiological study by also attending meetings of Part I Examiners and Part II Senior Organisers: I suspect that he would then feel reassured on the point he raises.

H. G. MORGAN Chief Examiner

\section{Memories of the Maudsley}

\section{DEAR SirS}

I am grateful to you for publishing the Maudsley JCR jottings with the memories and nostalgia that they evoked for me (Psychiatric Bulletin, December
$1989,13,689-694)$. Given their content you may be surprised that I can remember the time with great pleasure but whatever the failings of electric light, television etc, there was a great camaraderie among the junior staff and friendships began then that have lasted to this day. There was much stimulating discussion, albeit punctuated by a twist of the head to the rear, which for many years after would betray a Maudsley training.

For the sake of historical truth, it should be noted that there were concerns other than light bulbs and so on, and a capacity for direct action not revealed in these jottings. During my time as secretary to the JCR, the whole of the JCR collectively produced a document critical of many of the practices of that time. The wards were run in a rather archaic fashion with multiple consultants with little feeling for the multi-disciplinary team. There was very little thought to the ward as a therapeutic milieu and patients were often treated with less sensitivity, privacy, etc, than was appropriate. This document was presented to the consultant staff and to their credit it was accepted and resulted in substantial changes in practice at the Maudsley. Readers of the jottings will not be surprised to learn that Griffith Edwards and Jim Birley were in the forefront of this initiative.

\section{St Luke's Woodside Hospital}

O. W. HILL

Muswell Hill

London N10 $3 \mathrm{HU}$

\section{Invitation}

\section{Dear British Colleagues}

I am preparing a book on Gifts and Giving in Psychotherapy within a dynamic/analytical framework. In a psychotherapeutic context the different aspects of this fascinating issue are comprehensive: acceptance/ rejection, transference/counter-transference problems, gratitude/debt of gratitude, invasive motives, timing aspects, etc. At present I am in the phase of collecting clinical vignettes as dynamic illustrations to the theoretical sections in the book. In order to cover as many aspects as possible, you are invited to contribute to the book with 'gift-stories' from your consulting room. You are kindly requested to take the ethical implications of the project into account by 'camouflaging' your case-story - without missing the psychodynamic essence of it.

Department of Psychiatry $A$

JOACHIM KNOP Gentofte University Hospital DK-2900 Hellerup

Denmark 